University of Wollongong

Research Online

Australian Institute for Innovative Materials -

Papers

Australian Institute for Innovative Materials

$1-1-2018$

Synergistic amplification of catalytic hydrogen generation by a thin-film conducting polymer composite

\author{
Mohammed Alsultan \\ University of Wollongong, University of Mosul, mfka287@uowmail.edu.au \\ Jaecheol Choi \\ University of Mosul, jc878@uowmail.edu.au \\ Rouhollah Jalili \\ University of Mosul, rjalili@uow.edu.au \\ Pawel W. Wagner \\ University of Mosul, pawel@uow.edu.au \\ Gerhard F. Swiegers \\ University of Mosul, swiegers@uow.edu.au
}

Follow this and additional works at: https://ro.uow.edu.au/aiimpapers

Part of the Engineering Commons, and the Physical Sciences and Mathematics Commons

\footnotetext{
Research Online is the open access institutional repository for the University of Wollongong. For further information
} contact the UOW Library: research-pubs@uow.edu.au 


\title{
Synergistic amplification of catalytic hydrogen generation by a thin-film conducting polymer composite
}

\author{
Abstract \\ This work reports a composite of polylJ3,4-ethylenedioxythiophene) (PEDOT) that is notably more \\ catalytically active for hydrogen generation than the industry-standard benchmark catalyst, $\mathrm{Pt}$, under the \\ same conditions. A PEDOT thin-film containing nanoparticulate $\mathrm{Ni}$ (nano-Ni) and reduced graphene oxide \\ ( $r G O)$ in the specific molar ratio of 5.6 (C; PEDOT) : 1 (Ni) : 5.2 (C; other), (photo)catalytically generated H2 \\ at $3.6 \mathrm{~mA} \mathrm{~cm}-2$ (including ca. $0.2 \mathrm{~mA} \mathrm{~cm}-2$ due to the light illumination) after $3 \mathrm{~h}$ at $-0.75 \mathrm{~V}(\mathrm{vs}$. Ag/ \\ $\mathrm{AgCl}$ ) in $0.05 \mathrm{M} \mathrm{H} 2 \mathrm{SO} 4 / 0.2 \mathrm{M} \mathrm{Na} 2 \mathrm{SO} 4$ under 0.25 sun. A control nano-Ni/rGO film containing the same \\ quantities of nano-Ni and rGO but without any PEDOT, yielded $2.1 \mathrm{~mA} \mathrm{~cm}-2$, indicating that the PEDOT \\ synergistically amplified the above result by $71 \%$. Other ratios of the above PEDOT composite produced \\ notably lower activities. Control PEDOT, PEDOT/nano-Ni, and PEDOT/rGO films were an order of \\ magnitude less catalytically active. A control bare Pt electrode produced only $2.2 \mathrm{~mA} \mathrm{~cm}-2$ under the \\ same conditions. Studies suggested the origin of the synergistic amplification to involve the PEDOT \\ electrically connecting the largest number of active sites by the shortest, most efficient pathways for hole \\ transport. These results confirm the proposition that thin-film conducting polymers involving very specific, \\ optimum ratios of catalyst density to thickness may synergistically amplify catalysis.

\section{Disciplines} \\ Engineering | Physical Sciences and Mathematics

\section{Publication Details} \\ Alsultan, M., Choi, J., Jalili, R., Wagner, P. \& Swiegers, G. F. (2018). Synergistic amplification of catalytic \\ hydrogen generation by a thin-film conducting polymer composite. Catalysis Science \& Technology, 8 \\ (16), 4169-4179.
}




\section{Journal Name}

\section{ARTICLE}

\section{Synergistic Amplification of Catalytic Hydrogen Generation by a Thin-Film Conducting Polymer Composite}

Received 00th January 20xx Accepted 00th January 20xx

DOI: $10.1039 / \times 0 \times x 00000 x$

www.rsc.org/

\author{
Mohammed Alsultan, ${ }^{a, b}$ Jaecheol Choi, ${ }^{a}$ Rouhollah Jalili, ${ }^{a}$ Pawel Wagner ${ }^{a}$ and Gerhard F. \\ Swiegers*a
}

This work reports a composite of poly(3,4-ethylenedioxythiophene) (PEDOT) that is notably more catalytically active for hydrogen generation than the industry-standard benchmark catalyst, Pt, under the same conditions. A PEDOT thin-film containing nanoparticulate $\mathrm{Ni}$ (nano-Ni) and reduced graphene oxide ( $\mathrm{rGO}$ ) in the specific molar ratio of 5.6 (C; PEDOT) : 1 (Ni) : 5.2 (C; other), (photo)catalytically generated $\mathrm{H}_{2}$ at $3.6 \mathrm{~mA} / \mathrm{cm}^{2}$ (including ca. $0.2 \mathrm{~mA} / \mathrm{cm}^{2}$ due to the light illumination) after $3 \mathrm{~h}$ at $-0.75 \mathrm{~V}$ (vs $\mathrm{Ag} / \mathrm{AgCl}$ ) in $0.05 \mathrm{M} \mathrm{H}_{2} \mathrm{SO}_{4} / 0.2 \mathrm{M} \mathrm{Na}_{2} \mathrm{SO}_{4}$ under 0.25 sun. A control nano-Ni/rGO film containing the same quantities of nano-Ni and $\mathrm{rGO}$ but without any PEDOT, yielded $2.1 \mathrm{~mA} / \mathrm{cm}^{2}$, indicating that the PEDOT synergistically amplified the above result by $71 \%$. Other ratios of the above PEDOT composite produced notably lower activities. Control PEDOT, PEDOT/nano-Ni, and PEDOT/rGO films were an order of magnitude less catalytically active. A control bare Pt electrode produced only $2.2 \mathrm{~mA} / \mathrm{cm}^{2}$ under the same conditions. Studies suggested the origin of the synergistic amplification to involve the PEDOT electrically connecting the largest number of active sites by the shortest, most efficient pathways for hole transport. These results confirm the proposition that thin-film conducting polymers involving very specific, optimum ratios of catalyst density to thickness may synergistically amplify catalysis.

\section{Introduction}

Hydrogen $\left(\mathrm{H}_{2}\right)$ is widely considered to be the ideal fuel for a future clean, sustainable, and environmentally-friendly energy technology. ${ }^{1,2}$ Not only does hydrogen have a high energy density $(122 \mathrm{~kJ} / \mathrm{g}$ ) compared to fossil fuels (e.g. gasoline, $40 \mathrm{~kJ} / \mathrm{g}$ ), 3,4 but it is also non-polluting, generating only water as a waste product. For these reasons, the production of hydrogen via water-splitting in electrochemical (EC) or photo-electrochemical (PEC) cells, has been of particular interest. Conducting polymers (CPs) exhibit potentially useful properties as porous, conductive, and light-harvesting supports in catalytic hydrogen-generating ECS/PECs. ${ }^{5}$ Of the various, available CPs, poly(3,4-ethylenedioxythiophene) (PEDOT) is widely considered to be the most practical, thanks to its stability, capacity for electrochemical switching, conductivity, processability, and, in the case of photocatalysis, also its transparency to visible light. ${ }^{6}$ As a catalyst of the hydrogen evolution reaction (HER) $\left(2 \mathrm{H}^{+}+2 \mathrm{e}^{-} \rightarrow \mathrm{H}_{2}\right)$ however, virgin PEDOT generates only very small current densities that typically fall in the low $\mu \mathrm{A} / \mathrm{cm}^{2}$ range. For this reason, PEDOT is only of practical interest in combination with other materials and conductors, such as non-conducting polymers (e.g. polyethyleneglycol, PEG), ${ }^{7}$ carbon materials (e.g. single wall

\footnotetext{
a. Department of Science, University of Mosul, Mosul, Iraq

b. Intelligent Polymer Research Institute and ARC Centre of Excellenec for Electromaterials Science, University of Wollongong, Wollongong, NSW 2522, Australia.Email: Swiegers@uow.edu.au

Electronic Supplementary Information (ESI) available: Photographs and diagrams of cell used for gas studies; Pourbaix diagram for $\mathrm{Ni}, \mathrm{GC}$ trace of the gas collected. See DOI: $10.1039 / x 0 x x 00000 x$
}

carbon nanotubes), ${ }^{8}$ metallic nanoparticles (e.g. Pd), ${ }^{9}$ and lightactivated semiconductors (e.g. Si). ${ }^{10}$ While a number of studies have examined such thin-film PEDOT composites as HER catalysts, few have considered how PEDOT could be deployed to promote the highest possible catalytic activity. One study that did consider this question involved a PEDOT-PEG composite that was deposited on a Au-coated Gortex substrate. ${ }^{7(b)}$ That system yielded sustained current densities for HER catalysis of $2.2 \mathrm{~mA} / \mathrm{cm}^{2}$ at $-0.35 \mathrm{~V}$ (vs SCE) in strong acid ( $\left.1 \mathrm{M} \mathrm{H}_{2} \mathrm{SO}_{4}\right)$, that were closely comparable to that produced by the industry benchmark HER catalyst, Pt, under the same conditions. The high activity of the PEDOT-PEG derived from the large surface area of the Gortex substrate. The PEG also increased proton diffusion and overall conductivity. ${ }^{7(b)}$ To the best of our knowledge, this system is the most active reported PEDOTbased HER electrocatalyst as a proportion of the benchmark catalytic activity of Pt under the same settings.

In recent work we investigated the conditions under which thin-film conducting polymer supports like PEDOT may be induced to synergistically amplify water oxidation catalysis beyond what may be expected from the catalyst alone. ${ }^{11}$ That work suggested that the conducting polymer should electrically connect the largest number of catalytic sites by the shortest, least-resistive pathways to thereby achieve: (1) the greatest active area that is also: (2) the most responsive to the applied bias (minimizing the Tafel slope). ${ }^{11}$ That is, the connectivity, electron conductivity and catalytic capacity of the film should be matched. This was proposed to occur at very specific, optimum ratios of catalyst density to film conductivity and thickness. 
In this work we have sought to examine the same question as it relates to hydrogen generation catalysis, using a composite thin film comprising of PEDOT, nanoparticulate $\mathrm{Ni}$ (nano-Ni) as a catalyst, and reduced graphene oxide ( $\mathrm{rGO}$ ) as a conductor. Nano$\mathrm{Ni}$ is an $\mathrm{H}_{2}$-generating catalyst, while graphene oxide, which is normally insulating and hydrophobic, ${ }^{12,13}$ becomes conducting ${ }^{14-16}$ when reduced to $\mathrm{rGO} \cdot{ }^{17-24} \mathrm{~A}$ key difference with the earlier work ${ }^{11}$ is that the PEDOT conducting polymer is in its non-conducting form under the cathodic voltage bias conditions needed for hydrogen generation catalysis. As such, it was not clear whether synergistic amplifications beyond what may be expected from the catalyst alone could be achieved at all, nor whether they would follow the general principles that were observed for water oxidation catalysis.

We report that a $0.61 \mu \mathrm{m}$ thick film $\left(4.2 \mathrm{~cm}^{2}\right)$ of PEDOT containing the very specific ratio of $125 \mathrm{mg}$ nano-Ni and $5.4 \mathrm{mg} \mathrm{rGO}$ yields a sustained current density of $3.6 \mathrm{~mA} / \mathrm{cm}^{2}$ (including ca. 0.2 $\mathrm{mA} / \mathrm{cm}^{2}$ due to the light illumination) at $-0.75 \mathrm{~V}$ (vs $\mathrm{Ag} / \mathrm{AgCl}$ ) in 0.05 $\mathrm{M} \mathrm{H}_{2} \mathrm{SO}_{4} / 0.2 \mathrm{M} \mathrm{Na}_{2} \mathrm{SO}_{4}$ after $3 \mathrm{~h}$ under 0.25 sun. Other ratios produced notably lower activities. This was $64 \%$ higher than a benchmark, control bare Pt electrode, which produced $2.2 \mathrm{~mA} / \mathrm{cm}^{2}$ under identical conditions. It was also higher than a control film that contained only $125 \mathrm{mg}$ nano-Ni and $5.6 \mathrm{mg} \mathrm{rGO}$, without any PEDOT. The above settings represent the most favorable conditions for HER catalysis under which the nano-Ni is not susceptible to dissolution. Studies show that, like the earlier study involving water oxidation catalysis, the synergistic amplification appears to have derived from the PEDOT connecting the largest number of catalytic sites by the shortest, most efficient pathway for charge carrier conduction. In this case however, the charge carriers were holes $\left(\mathrm{h}^{+}\right)$and the conduction process involved hole transport. The above thin-film appears to be the most active PEDOT-based HER catalyst yet reported as a proportion of the catalytic activity of Pt under the same conditions.

\section{Results and Discussion}

\section{CV studies of control firms of nano-Ni/rGO on FTO glass}

In the first stage of this study, we sought to determine the most favourable $\mathrm{pH}$ and voltage bias conditions under which HER catalysis by the proposed composite PEDOT/nano-Ni/rGO thin films could be studied without degradation of the films. As PEDOT is known to be stable under even strongly reducing conditions in $1 \mathrm{M}$ $\mathrm{H}_{2} \mathrm{SO}_{4}(\mathrm{pH} 0.3),{ }^{7(\mathrm{~b})}$ we studied thin-film mixtures of nano-Ni and $\mathrm{rGO}$ only (without any PEDOT) that had been spin-coated onto FTO glass and dried. These films proved to bind robustly to the FTO glass. The nano-Ni had an average diameter of $20 \mathrm{~nm}$; the rGO was prepared as described in the Experimental Section.

To assess the best conditions for HER catalysis by these thinfilms, without degradation, we measured their $\mathrm{CV}$ s under reducing conditions $(-0.25 \mathrm{~V}$ to $-1.1 \mathrm{~V}$ vs $\mathrm{Ag} / \mathrm{AgCl})$ without light illumination, over a range of $\mathrm{pHs}(0-12)$. At a $\mathrm{pH}$ of 0 , the nano- $\mathrm{Ni} / \mathrm{rGO}$ films delaminated from the FTO glass, suggesting that one of the components degraded. However, the films were stable to delamination at $\mathrm{pH}^{\prime} \mathrm{s}$ of 1 and above.

Films having a wide variety of weight ratios of nano-Ni : rGO were studied. All displayed characteristic HER catalytic currents (Figure 1). One film, having the weight ratio of $125 \mathrm{mg}$ nano-Ni : 6

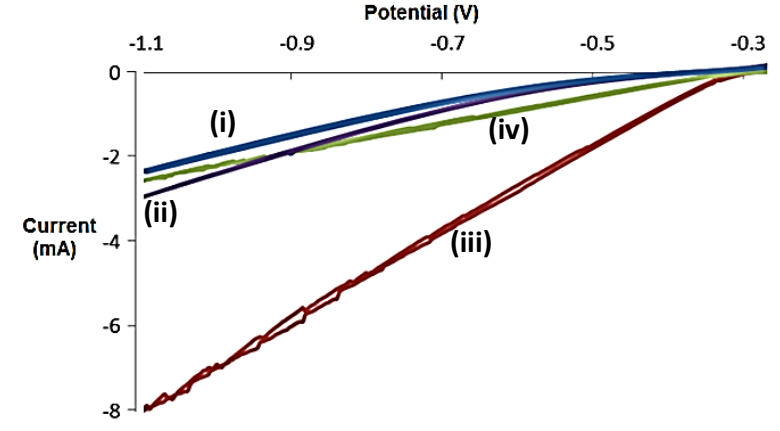

Figure 1. Cyclic voltammograms (vs $\mathrm{Ag} / \mathrm{AgCl}$ ) in $0.05 \mathrm{M} \mathrm{H}_{2} \mathrm{SO}_{4} / 0.2 \mathrm{M}$ $\mathrm{Na}_{2} \mathrm{SO}_{4}$, without light illumination, of FTO glass slides having $1 \mathrm{~cm}^{2}$ active geometric area, coated with: (i)-(ii) nano-Ni/rGO (ratio $125 \mathrm{mg}$ nano-Ni : $6 \mathrm{mg} \mathrm{rGO}$ ), (i) immediately after preparation and (ii) after 15 scans; or: (iii)-(iv) $100 \mathrm{~nm}$ of sputter-coated Pt, (iii) immediately after preparation and (iv) after 15 scans. Scan rate: $5 \mathrm{mV} / \mathrm{s}$.

mg rGO appeared to be the most active. The relative current densities of this film at $-1.1 \mathrm{~V}$ (vs $\mathrm{Ag} / \mathrm{AgCl}$ ) during scanning increased from ca. $1.2 \mathrm{~mA} / \mathrm{cm}^{2}$ at pH 12 to ca. $3 \mathrm{~mA} / \mathrm{cm}^{2}$ at $\mathrm{pH}$ 1. By contrast, an equivalent, sputtered, bare Pt film on an FTO glass slide yielded, at $\mathrm{pH} 1$, an onset potential of $0.32 \mathrm{~V}$ and a current density of ca. $8 \mathrm{~mA} / \mathrm{cm}^{2}$ at $-1.1 \mathrm{~V}$ (vs $\mathrm{Ag} / \mathrm{AgCl}$ ) (Figure 1 ).

It therefore appeared advantageous to study the proposed PEDOT/Nano-Ni/rGO composite films at a $\mathrm{pH}$ of 1 . However, the Pourbaix diagram for $\mathrm{Ni}$ (Figure S2) indicated that at $\mathrm{pH} 1, \mathrm{Ni}$ is susceptible to dissolution with subsequent formation of soluble $\mathrm{Ni}(\mathrm{II})$ at potentials more positive than $-0.375 \mathrm{~V}$ vs SHE $(-0.605 \mathrm{~V}$ vs $\mathrm{Ag} / \mathrm{AgCl}$ ). At potentials more negative than this, $\mathrm{Ni}$ is favored to remain a solid metal. Accordingly, it was decided to study the proposed PEDOT/nano-Ni/rGO composite films on FTO glass slides in $0.05 \mathrm{M} \mathrm{H}_{2} \mathrm{SO}_{4} / 0.2 \mathrm{M} \mathrm{Na}_{2} \mathrm{SO}_{4}$ (pH 1) at potentials of $-0.75 \mathrm{~V}$ vs $\mathrm{Ag} / \mathrm{AgCl}$, which was well clear of the $-0.605 \mathrm{~V}$ threshold.

Chronoamperometric Studies of films of Nano-Ni, rGO, PEDOT, PEDOT/Nano-Ni, PEDOT/rGO, and PEDOT/Nano-Ni/rGO on FTO

In the second stage of this work, we prepared PEDOT thin-films incorporating nano-Ni and/or rGO on FTO glass, using vapour phase polymerization. This technique involved spin-coating a fixed, small volume of an ethanol solution of Fe(III)-pTS oxidant $(100 \mathrm{mg})$ that may contain nano-Ni and/or rGO onto an FTO glass slide $\left(4.2 \mathrm{~cm}^{2}\right)$. The slide was then dried and suspended in a sealed flask above liquid 3,4-ethylenedioxythiophene (EDOT), causing the formation of a PEDOT film of $55-65 \mu \mathrm{m}$ thickness. The film was thoroughly washed to remove excess Fe and then dried.

The following samples were prepared on FTO glass slides: (i) PEDOT alone (control), (ii) PEDOT containing nano-Ni alone (control), (iii) PEDOT containing rGO alone (control), and (iv) PEDOT containing various mixtures of nano-Ni and $\mathrm{rGO}$. Each of the films were prepared by incorporating nano-Ni (0-250 mg) and/or rGO (0$6 \mathrm{mg}$ ) in the spin-coating solution for vapour-phase polymerisation, with a uniformly thin PEDOT layer then being formed around them.

Chronoamperograms were thereafter measured at $-0.75 \mathrm{~V}$ vs $\mathrm{Ag} / \mathrm{AgCl}$ for each sample, as a working electrode in $0.05 \mathrm{M} \mathrm{H}_{2} \mathrm{SO}_{4}$ / $0.2 \mathrm{M} \mathrm{Na}_{2} \mathrm{SO}_{4}$, with and without light illumination using a SoLux daylight MR16 halogen light bulb (0.25 sun intensity). The earlier prepared films of nano-Ni/rGO were also tested. A large Pt mesh 


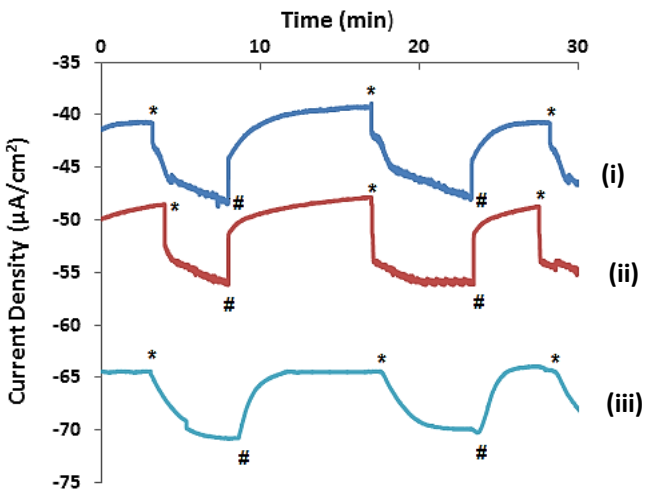

Figure 2. Chronoamperograms at $-0.75 \mathrm{~V}$ (vs $\mathrm{Ag} / \mathrm{AgCl}$ ) in $0.05 \mathrm{M}$ $\mathrm{H}_{2} \mathrm{SO}_{4} / 0.2 \mathrm{M} \mathrm{Na}_{2} \mathrm{SO}_{4}$, after $3 \mathrm{~h}$ of operation, with and without light illumination ( 0.25 sun), of FTO glass slides coated with: (i) PEDOT alone, (ii) PEDOT/nano-Ni (125 mg nano-Ni), and (iii) PEDOT/rGO (5.4 mg rGO) (*'='light on', \#='light off). Note that the data in graph (b) is in $\mathrm{mA} / \mathrm{cm}^{2}$ and therefore substantially larger than the data in graph (a), which is in $\mu \mathrm{A} / \mathrm{cm}^{2}$.

served as the counter electrode.

The control films containing PEDOT only produced low current densities of ca. $46 \mu \mathrm{A} / \mathrm{cm}^{2}$ (including a ca. $5 \mu \mathrm{A} / \mathrm{cm}^{2}$ photocurrent due to the light illumination) (Figure 2(a)(i)). A control PEDOT/nano$\mathrm{Ni}$ film containing $125 \mathrm{mg}$ nano-Ni yielded a higher, but still low current density of ca. $56 \mu \mathrm{A} / \mathrm{cm}^{2}$ (including ca. $9 \mu \mathrm{A} / \mathrm{cm}^{2}$ due to the light illumination) (Figure 2(a)(ii)). A control PEDOT/rGO film containing $5.4 \mathrm{mg} \mathrm{rGO}$ generated ca. $70 \mu \mathrm{A} / \mathrm{cm}^{2}$ (including ca. 6 $\mu \mathrm{A} / \mathrm{cm}^{2}$ due to the light illumination) (Figure 2(a)(iii)). The low currents suggested that the PEDOT in the control films was coating the additives, particularly the nano-Ni catalyst, and blocking their catalytic activity.

Remarkably however, this did not prove to be a problem with the PEDOT/nano-Ni/rGO films, the most active of which contained $125 \mathrm{mg}$ nano-Ni and $5.4 \mathrm{mg} \mathrm{rGO}$, and yielded a current density of around $3.6 \mathrm{~mA} / \mathrm{cm}^{2}\left(=3600 \mu \mathrm{A} / \mathrm{cm}^{2}\right.$; including ca. $200 \mu \mathrm{A} / \mathrm{cm}^{2}$ due to the light illumination) (Figure $3(i))$. This was about 60-times the current densities of the equivalent PEDOT-containing control films.

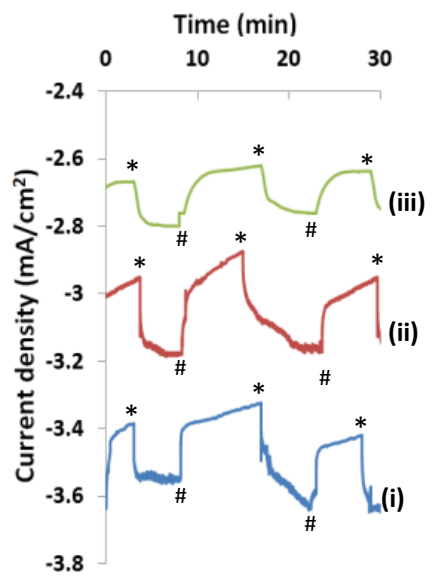

Figure 3. Chronoamperograms at $-0.75 \mathrm{~V}$ (vs $\mathrm{Ag} / \mathrm{AgCl}$ ) in $0.05 \mathrm{M}$ $\mathrm{H}_{2} \mathrm{SO}_{4} / 0.2 \mathrm{M} \mathrm{Na}_{2} \mathrm{SO}_{4}$ of FTO glass slides coated with: PEDOT/nano$\mathrm{Ni} / \mathrm{rGO}$ coatings after $3 \mathrm{~h}$, with and without light illumination, where the coatings all contained $125 \mathrm{mg}$ nano-Ni but with (b)(i) $5.4 \mathrm{mg} \mathrm{rGO}$, (b)(ii) $6.0 \mathrm{mg} \mathrm{rGO}$, or (b)(iii) $4.8 \mathrm{mg}$ rGO (*'='light on', \#='light off).
An interesting feature of the performance of the PEDOT/nano$\mathrm{Ni} / \mathrm{rGO}$ films was what can only be described as an extreme sensitivity to the proportion of rGO present. The maximum catalytic performance was obtained when the film was made using $5.4 \mathrm{mg}$ rGO in the spin-coated polymerisation solution (Figure 3(i)). The presence of a mere $0.6 \mathrm{mg}$ more $\mathrm{rGO}(6.0 \mathrm{mg})$ or $0.6 \mathrm{mg}$ less $\mathrm{rGO}$ $(4.8 \mathrm{mg})$ in the film led to significant declines in the catalytic activity; namely, to $3.2 \mathrm{~mA} / \mathrm{cm}^{2}$ (Figure 3 (ii)) and $2.8 \mathrm{~mA} / \mathrm{cm}^{2}$ (Figure 3(iii)), respectively, after $3 \mathrm{~h}$ under light illumination. Such extreme sensitivity is highly characteristic of a synergistic effect. A lesser sensitivity was seen for the nano-Ni, with the use of $135 \mathrm{mg}$ or $110 \mathrm{mg}$ decreasing the current by around $0.2-0.3 \mathrm{~mA} / \mathrm{cm}^{2}$. This is consistent with decreased light absorption.

The relatively slow rise times of the photocurrents after the light illumination was switched on has been observed before, and is characteristic of PEDOT. ${ }^{25}$

As shown in Figure 4, the current density after $3 \mathrm{~h}$ under light illumination of the PEDOT/nano-Ni/rGO film containing $125 \mathrm{mg}$ nano-Ni and $5.4 \mathrm{mg}$ rGO $\left(3.6 \mathrm{~mA} / \mathrm{cm}^{2}\right.$; Figure $\left.4(\mathrm{i})\right)$ substantially exceeded that produced by an equivalent nano-Ni/rGO film, without PEDOT, containing the same ratio of nano-Ni : $r G O$ of 125 $\mathrm{mg}$ : $5.4 \mathrm{mg}\left(2.1 \mathrm{~mA} / \mathrm{cm}^{2}\right.$; Figure 4(ii)). The presence of the PEDOT therefore added at least $1.5 \mathrm{~mA} / \mathrm{cm}^{2}$ (or $70 \%$ ) to the current density. Gas bubbles could be clearly seen to form and release on both films.

By contrast, the bare Pt control electrode generated only ca. 2.2 $\mathrm{mA} / \mathrm{cm}^{2}$ under the same conditions (Figure 4(iii)), which was comparable to the control nano-Ni/rGO film without PEDOT (Figure 4(ii)). Pt is well-known to initially be highly active in strong acids, with its activity thereafter declining sharply, especially over the first $1 \mathrm{~h}$ of operation. ${ }^{26}$ As can be seen in Figure 4(iii), its current density stabilized at a level well below that of the PEDOT/nano-Ni/rGO thinfilm composite (Figure 4(i)). The presence of the PEDOT was clearly critical to the superior performance.

\section{Gas Collection Studies of PEDOT/Nano-Ni/rGO on FTO}

To determine the identity of the bubbles formed on the most active

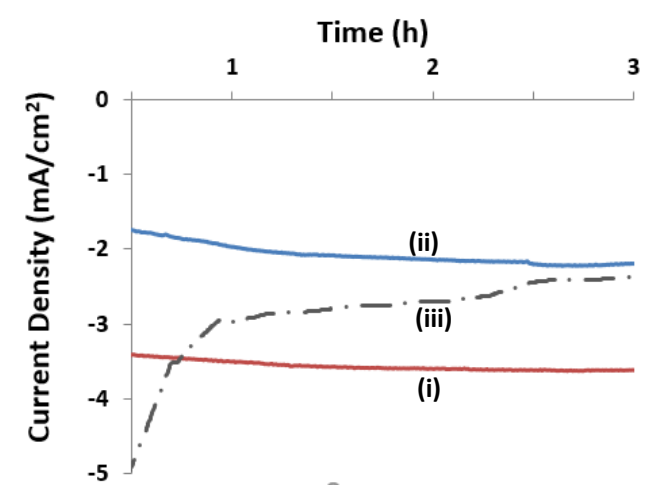

Figure 4. Chronoamperograms at $-0.75 \mathrm{~V}$ (vs $\mathrm{Ag} / \mathrm{AgCl}$ ) in $0.05 \mathrm{M} \mathrm{H}_{2} \mathrm{SO}_{4} / 0.2 \mathrm{M}$ $\mathrm{Na}_{2} \mathrm{SO}_{4}$ of FTO glass slides coated with: (i) PEDOT/nano-Ni/rGO (125 mg nano-Ni/5.4 mg rGO; with light illumination), (ii) nano-Ni/rGO without PEDOT (control) (125 mg nano-Ni/5.4 mg rGO; with light illumination), and (iii) bare $\mathrm{Pt}$ (control) (without light illumination). 


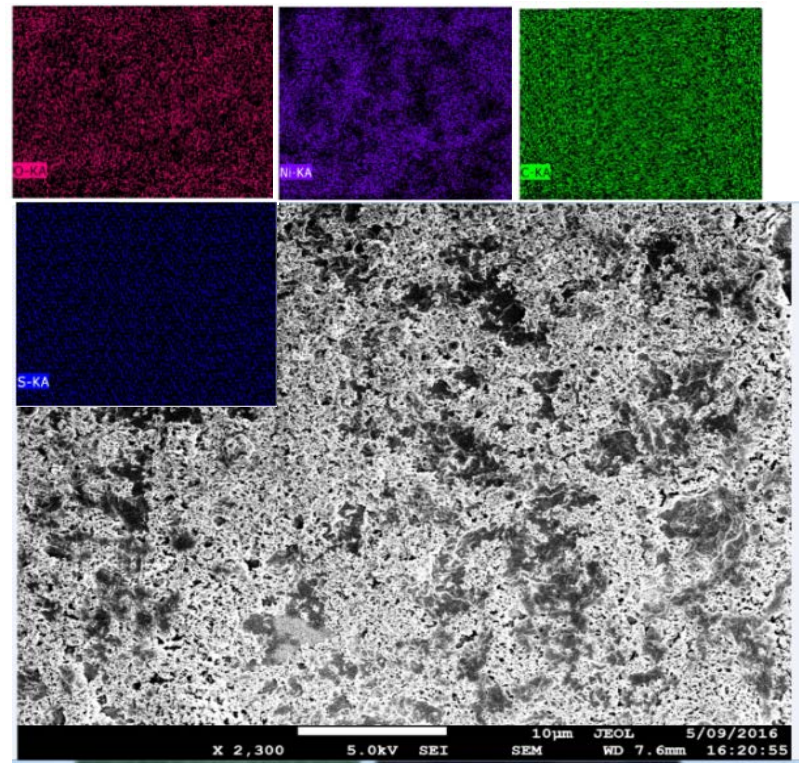

Figure 5. (a) Scanning electron microscope image of PEDOT/Nano$\mathrm{Ni} / \mathrm{rGO}$ containing $125 \mathrm{mg}$ nano-Ni and $5.4 \mathrm{mg} \mathrm{rGO}$. The inset images show the elemental distributions, using EDX, of: (b) O, (c) $\mathrm{Ni}$, (d) C, (e) $\mathrm{S}$, and (f) $\mathrm{O}, \mathrm{Ni}, \mathrm{C}, \mathrm{S}$ together.

PEDOT/Nano-Ni/rGO thin film, we collected and tested the gas produced using a specialized, sealed cell (Figure S1) connected to a dedicated gas chromatograph (as described in the Experimental Section). In addition to the Ar carrier gas, the GC trace contained only a single peak whose retention time corresponded to hydrogen (Figure S3). Peaks due to other gases, including air nitrogen and/or oxygen, were notably absent. Gas bubbles formed on the Pt mesh counter electrode were separately shown to be pure oxygen using the same equipment.

The PEDOT/nano-Ni/rGO film therefore clearly catalysed the $\mathrm{HER}$, with the nano-Ni/rGO components likely producing about $60 \%$ of the electrocatalytic effect and a synergistic amplification arising from the PEDOT accounting for the rest. The light-induced current density comprised only about $5 \%$ of the total.

\section{Characterisation of the PEDOT/Nano-Ni/rGO Electrode}

To determine the composition of the most active PEDOT/Nano$\mathrm{Ni} / \mathrm{rGO}$ film on the working electrode, elemental analysis studies were undertaken. Given that the quantity of material in such films was far below the minimum needed for an elemental analysis, multiple identical films were prepared, dried, carefully scraped off the FTO glass, and combined.

Analysis of the combined films indicated that they contained $22.00 \% \mathrm{Ni}, 11.30 \% \mathrm{~S}, 48.70 \% \mathrm{C}$ and no Fe. As only the PEDOT contained the element $\mathrm{S}$, while $\mathrm{rGO}$ contained only $\mathrm{C}$ and the nano$\mathrm{Ni}$ only $\mathrm{Ni}$, it was possible to calculate the molar ratio of PEDOT : $\mathrm{Ni}$ : rGO to be 5.6 (C; PEDOT) : 1 (Ni) : 5.2 (C; other). As there are 6 $\mathrm{C}$ atoms in each PEDOT monomer, this equated to a ratio of 0.93 PEDOT monomers to every $1 \mathrm{Ni}$ atom.

Scanning Electron Microscopy (SEM), Transmission Electron Microscopy (TEM), X-ray powder diffraction (XRD), and X-ray photoelectron spectroscopy (XPS) analyses were also performed on the PEDOT/nano- $\mathrm{Ni} / \mathrm{rGO}$ films prior to and after catalytic testing in order to assess structural and chemical changes in the catalytic film.

Figure 5(a) depicts a representative SEM image of the PEDOT/nano-Ni/rGO film after $3 \mathrm{~h}$ of operation, showing that its surface had developed a large number of vacant, nanoscopic pores. Indeed, the surface (and presumably the film) had become highly porous. This stands in contrast with Figure S4, which depicts the surface of the film prior to catalysis; no such pore structure was visible.

Measurements also showed that the above PEDOT/nano$\mathrm{Ni} / \mathrm{rGO}$ film, which had been prepared as a layer that was $0.61 \pm 2$ $\mu \mathrm{m}$ thick, had swelled to $\sim 0.85 \mu \mathrm{m}$ thickness upon immersion for 5 min in the $0.05 \mathrm{M} \mathrm{H}_{2} \mathrm{SO}_{4} / 0.2 \mathrm{M} \mathrm{Na}_{2} \mathrm{SO}_{4}$ electrolyte. After $3 \mathrm{~h}$ of operation, it was $\sim 0.98 \mu \mathrm{m}$ thick. Clearly, the PEDOT/nano-Ni/rGO film swelled and became notably more porous during operation.

TEM showed the PEDOT to separately envelope each of the nano-Ni and the rGO platelets, with little contact between the nano-Ni and the rGO present. The PEDOT generally made seamless contact with the $\mathrm{Ni}$ lattice and with the $\mathrm{rGO}$. There was no observable change to these interfaces, as seen using TEM, after $3 \mathrm{~h}$ of operation. This suggested that the porosity derived from the PEDOT itself becoming more porous and not from a change in the distribution or location of the nano-Ni and $\mathrm{rGO}$ within the PEDOT.

Figure 6 depicts $X$-ray powder diffraction (XRD) data for the PEDOT/nano-Ni/rGO film, as compared to control PEDOT (undoped), rGO, and its parent GO. The data did not substantially change over $3 \mathrm{~h}$ of operation. As can be seen, the XRD of the GO displayed a distinctive diffraction peak at $2 \theta=$ $10.27^{\circ}$ due to the (002) carbon crystalline plane, revealing the presence of oxygen functional groups on the graphite sheets. ${ }^{27-32}$ The XRD scan of the rGO shows, however, that the sharp peak at $10.2^{\circ}$ had disappeared and been replaced by a new broad peak centred at $22.90^{\circ}$, consistent with the oxygen

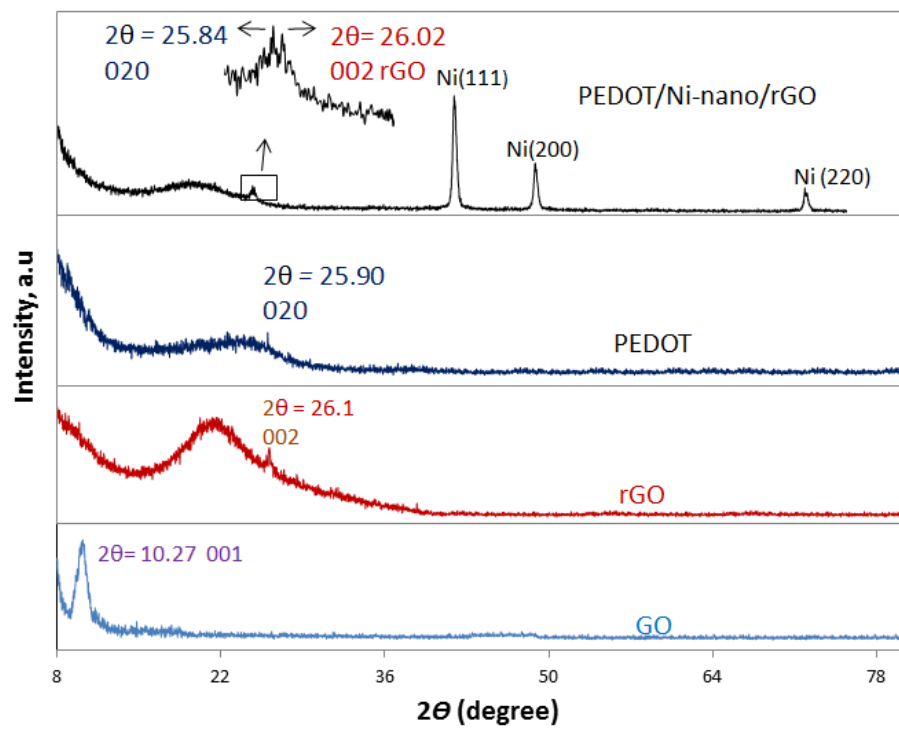

Figure 6. Powder X-ray diffraction (XRD) of PEDOT/Nano-Ni/rGO containing $125 \mathrm{mg}$ nano-Ni and $5.4 \mathrm{mg} \mathrm{rGO}$, relative to control PEDOT, control rGO, and control GO. 
(a) $S 2 p$

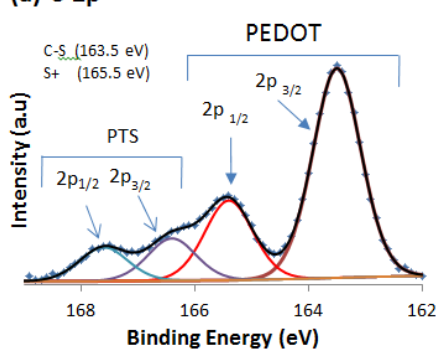

(b) $\mathrm{C} 1 \mathrm{~s}$

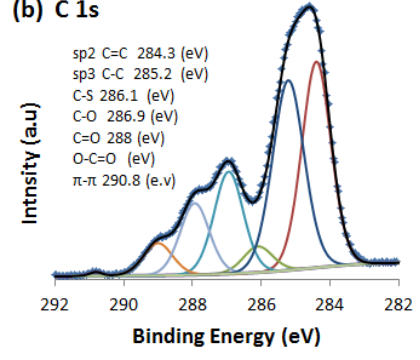

(c) $01 \mathrm{~s}$
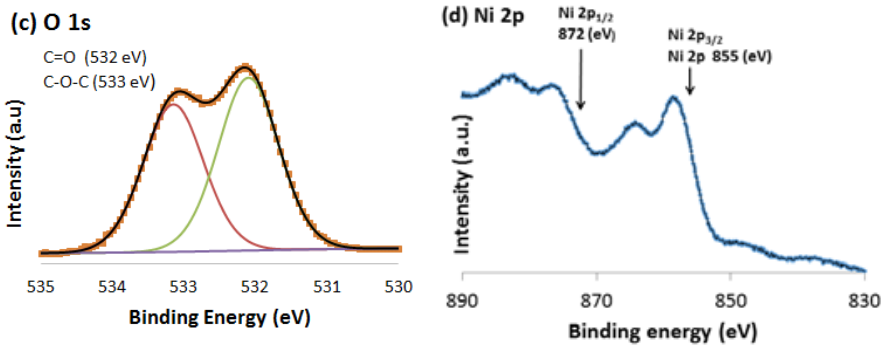

Figure 7. X-ray photoelectron spectroscopy (XPS) of PEDOT/Nano$\mathrm{Ni} / \mathrm{rGO}$ containing $125 \mathrm{mg}$ nano-Ni and $5.4 \mathrm{mg} \mathrm{rGO}$, showing measured data (individual data points) and modelled data (solid black lines) for the: (a) S 2p, (b) C 1s, (c) O 1s, (d) Ni 2p spectra.

functionalities being significantly reduced. ${ }^{33,34}$ As well, a clear diffraction peak at $26.1^{\circ}$, due to the (002) plane in the shortrange order of stacked graphene sheets, was visible. ${ }^{35,36}$ The XRD of pure PEDOT exhibited a peak at $2 \theta=25.90^{\circ}$ which could be attributed to the (020) reflection due to the intermolecular spacing of the polymer backbone. ${ }^{37,38}$ The XRD of the PEDOT/nano-Ni/rGO film also displayed a broad peak at $2 \theta=17-25^{\circ}$ due to the $\mathrm{rGO}$, as well as two peaks at $2 \theta 25.84^{\circ}$ and $26.02^{\circ}$ due to the combination of the PEDOT and the rGO. A pattern of three peaks at $44.52^{\circ}, 51.80^{\circ}$ and $76.35^{\circ}$ were due to the $\mathrm{Ni}(111), \mathrm{Ni}(200)$ and $\mathrm{Ni}(220)$ planes, confirming the presence of the face centered cubic (fcc) structure of nickel in the nanoparticles. ${ }^{39}$

To determine whether the catalysis altered the chemical states and elemental composition of the PEDOT/nano-Ni/rGO film, it was analysed using XPS at the commencement of, and after $3 \mathrm{~h}$ of operation. The resulting spectra, which were substantially similar, are depicted by the individual data points in Figure 7. The modelled spectra, shown by the solid black lines in Figure 7, closely matched the experimental data, shown by the colour data points. The XPS spectra of the PEDOT/nano-Ni/rGO film did not substantially change if the rGO present was varied from $4.8 \mathrm{mg}$ to $6.0 \mathrm{mg}$.

The main peaks corresponded to $\mathrm{O} 1 \mathrm{~s}, \mathrm{C} 1 \mathrm{~s}, \mathrm{Ni} 2 \mathrm{p}$ and $\mathrm{S}$ $2 \mathrm{p}$. The $\mathrm{O} 1 \mathrm{~s}$ and $\mathrm{C} 1 \mathrm{~s}$ spectra were associated with both PEDOT and $\mathrm{rGO}$, while the $\mathrm{S} 2 \mathrm{~s}$ spectrum derived only from the PEDOT. The $C$ 1s spectrum contained four deconvolution peaks at 284.5, 285.2, 286.90 and $289 \mathrm{eV}$ (Figure 7(b)). The peak at $284.5 \mathrm{eV}$ represented a $\mathrm{sp}^{2}$ carbon hybrid, which related to the $\mathrm{C}=\mathrm{C}$ binding energy. The peak at $285.2 \mathrm{eV}$ represented a $\mathrm{sp}^{3}$ carbon hybrid and related to $\mathrm{C}-\mathrm{S}, \mathrm{C}-\mathrm{C}$, and/or $\mathrm{C}-\mathrm{H}$ binding energies. Finally, the peaks at 288.0 and $289.0 \mathrm{eV}$ related to $\mathrm{C}=\mathrm{O}$ and $\mathrm{O}-\mathrm{C}=\mathrm{O}$ binding energies, respectively. ${ }^{40-49}$ The $\mathrm{S} 2 \mathrm{p}$ spectrum contained peaks at 163.5 and $165.5 \mathrm{eV}$, which related to the binding energy of the $2 p_{3 / 2}$ and $2 p_{1 / 2}$ that correspond to the $\mathrm{C}-\mathrm{S}$ bond and $\mathrm{S}^{+}$. These were assigned to the $S$ atoms of the PEDOT fragments. The other two small peaks relate to the $2 p_{3 / 2}$ and $2 p_{1 / 2}$ of the sulfonic groups in the PTS structure. ${ }^{50-53}$ The $O 1 \mathrm{~s}$ spectrum of the film displayed two peaks at 532 and $533.4 \mathrm{eV}$. These related to the binding energy of $\mathrm{C}=\mathrm{O}$ and/or $\mathrm{C}-\mathrm{O}$ bonds respectively. ${ }^{54-56}$ Finally, the $\mathrm{Ni} 2 \mathrm{p}$ spectra exhibited two main peaks at 855 and $872 \mathrm{eV}$, relating to $1 / 2$ and $3 / 2$ spin respectively.
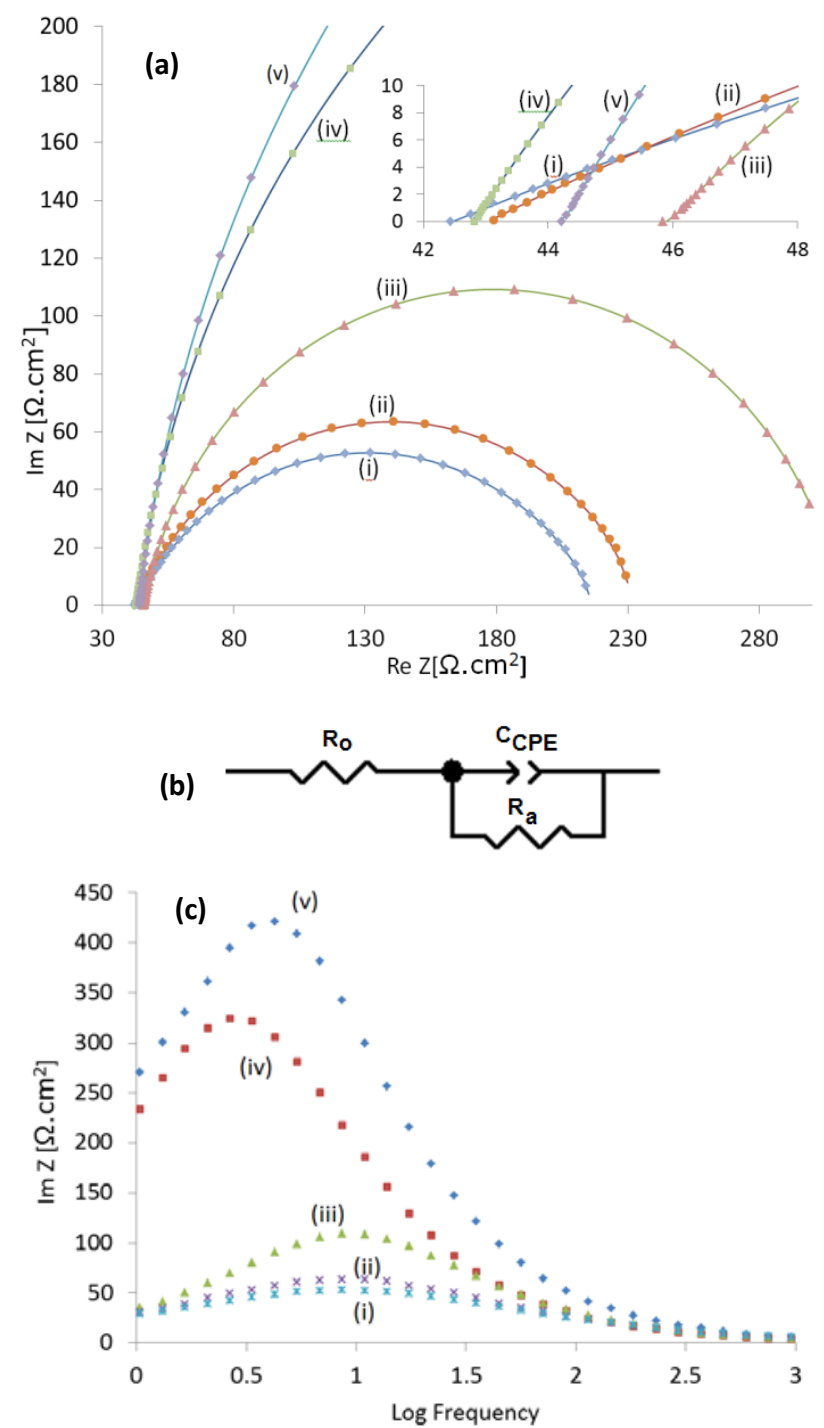

Figure 8. (a) Nyquist plot, (b) equivalent circuit, and (c) Bode plot; at $0.75 \mathrm{~V}$ (vs Ag/AgCl); showing measured data (individual data points) and modelled data (solid lines) (modelled using the equivalent circuit depicted in (b)), for: (i) PEDOT/nano-Ni/rGO containing $125 \mathrm{mg}$ nano$\mathrm{Ni}$ and $5.4 \mathrm{mg}$ rGO (with light illumination), (ii) PEDOT/nano-Ni/rGO containing $125 \mathrm{mg}$ nano- $\mathrm{Ni}$ and $5.4 \mathrm{mg} \mathrm{rGO}$ (without light illumination), (iii) control nano-Ni/rGO (without PEDOT) containing 125 $\mathrm{mg}$ nano-Ni and $5.4 \mathrm{mg} \mathrm{rGO}$ (with light illumination), (iv) control PEDOT only (with light illumination), and (v) control PEDOT only (without light illumination). 


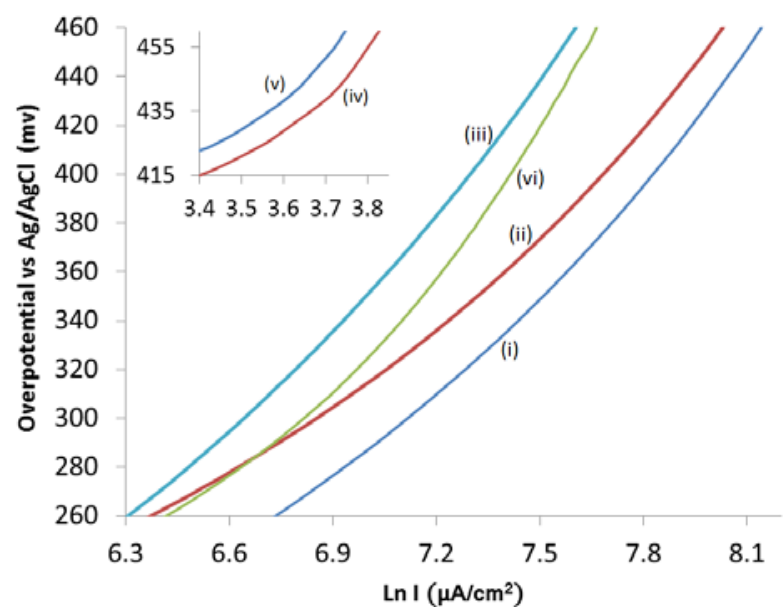

Figure 9. Tafel plots for: (i) PEDOT/nano-Ni/rGO containing $125 \mathrm{mg}$ nano- $\mathrm{Ni}$ and $5.4 \mathrm{mg} \mathrm{rGO}$ (with light illumination), (ii) PEDOT/nano$\mathrm{Ni} / \mathrm{rGO}$ containing $125 \mathrm{mg}$ nano-Ni and $5.4 \mathrm{mg} \mathrm{rGO}$ (without light illumination), (iii) control nano-Ni/rGO (without PEDOT) containing 125 $\mathrm{mg}$ nano-Ni and $5.4 \mathrm{mg} \mathrm{rGO}$ (with light illumination), (iv) control PEDOT only (with light illumination), (v) control PEDOT only (without light illumination), and (vi) control bare Pt.

\section{Electrochemical Impedance Spectroscopy (EIS) and Tafel Plot studies of the PEDOT/Nano-Ni/rGO}

To better understand the mechanism of the catalysis, we performed EIS and Tafel plot measurements on the most active $\mathrm{PEDOT} / \mathrm{nano}-\mathrm{Ni} / \mathrm{rGO}$ electrode and compared them to the control films of nano-Ni/rGO (without PEDOT) containing $125 \mathrm{mg}$ nano-Ni and $5.4 \mathrm{mg} \mathrm{rGO}$, control bare Pt, and control PEDOT alone, with and without light illumination. The individual data points in Figure 8(a) and Figure 8(c) depict the measured data from the EIS studies. The bare Pt control produced haphazard, irreproducible data due, most likely, to interference arising from gas bubble formation, and is not depicted. Figure 9 shows the Tafel plots.

As can be seen in the Nyqist and corresponding Bode plots (Figures $8(a),(c))$, the performance of the control PEDOT samples, with and without illumination, were governed by diffusion processes with frequencies about the $10^{0.5} \mathrm{~Hz}$ range. The nano$\mathrm{Ni} / \mathrm{rGO}$ and PEDOT/nano-Ni/rGO samples (with and without illumination) were, however, dominated by processes at intermediate frequencies $\left(10^{1-1.5} \mathrm{~Hz}\right)$, which are more typical of interfacial and solution catalytic charge transfer processes, like adsorption. ${ }^{57}$ High frequency components at $10^{3-4} \mathrm{~Hz}$ were not observed (Figure $8(a)$ inset). It can be concluded that catalytic hydrogen generation by nano-Ni/rGO and PEDOT/nano-Ni/rGO (with and without light illumination) was kinetically controlled and involved the same catalytic sites.

Accordingly, we modelled the EIS data using the equivalent circuit depicted in Figure 8(b), as used previously. ${ }^{57-63}$ The modelled data is shown as the solid lines in Figure 8(a). As can be seen, there is an excellent match between the measured data and the modelled data. Table 1 provides results deriving from the modelling, including the ohmic resistance, $R_{0}$, solution/interfacial/charge transfer resistance, $R_{c t}$, and capacitance, which was expressed in terms

\begin{tabular}{|c|c|c|c|c|c|c|c|}
\hline Sample & $\begin{array}{l}\mathrm{R}_{0} \\
(\Omega \\
\left.\mathrm{cm}^{2}\right)\end{array}$ & $\begin{array}{l}\mathrm{R}_{\mathrm{ct}} \\
(\Omega \\
\left.\mathrm{cm}^{2}\right)\end{array}$ & $\begin{array}{c}\text { QCPE } \\
(\mu \Omega \\
{ }^{1} \mathrm{Cm} \\
\left.{ }^{2} \mathrm{~s}^{n}\right)\end{array}$ & $\mathrm{n}_{\mathrm{CPE}}$ & $\begin{array}{l}\mathrm{C}_{\mathrm{CPE}} \\
(\mu \mathrm{Fcm}-2 \\
\left.\times 10^{4}\right)\end{array}$ & $\begin{array}{c}\mathrm{A} \\
(\mathrm{mV} / \mathrm{dec})\end{array}$ & $\begin{array}{c}\dot{i}_{0} \\
(\mu \mathrm{A} \\
\left.\mathrm{cm}^{2}\right)\end{array}$ \\
\hline $\begin{array}{l}\text { PEDOT } \\
\text { (dark) }\end{array}$ & 43.57 & 1005 & 96.32 & 0.80 & 2.43 & 70.24 & 14.80 \\
\hline PEDOT (light) & 42.81 & 749.2 & 105.0 & 0.80 & 2.69 & 68.31 & 15.74 \\
\hline $\begin{array}{l}\text { Nano-Ni/rGO } \\
\text { (light) }\end{array}$ & 45.84 & 265.6 & 142.0 & 0.81 & 4.20 & 58.72 & 9.07 \\
\hline $\begin{array}{l}\text { PEDOT/nano- } \\
\mathrm{Ni} / \mathrm{rGO} \text { (dark) }\end{array}$ & 43.38 & 189.5 & 156.0 & 0.80 & 4.25 & 57.74 & 6.45 \\
\hline $\begin{array}{l}\text { PEDOT/nano- } \\
\text { Ni/rGO (light) }\end{array}$ & 42.43 & 173.8 & 165.0 & 0.81 & 4.71 & 47.83 & 6.67 \\
\hline $\mathrm{Pt}$ & --- & ---- & ---- & --- & ----- & 58.35 & 7.02 \\
\hline
\end{tabular}

Table 1. Data from modelling of the EIS results in Figure 8 (ohmic resistance, $R_{o}$, charge transfer resistance, $R_{c t}$, and charge transfer capacitance $\left(C_{c t}\right)$ expressed in terms of a constant phase element ( $\mathrm{n}_{\mathrm{CPE}}$, and $\left.\mathrm{C}_{\mathrm{CPE}}\right) ;{ }^{64}$ and Tafel plots (slope $\mathrm{A}$; exchange current density $i_{0}$ ). The equivalent circuit in Figure $8(\mathrm{~b})$ was used to model the EIS data. ('dark' = without light illumination; 'light' = with light illumination).

of a constant phase element ( $\mathrm{n}_{\mathrm{CPE}}$, and $\left.\mathrm{C}_{\mathrm{CPE}}\right) .{ }^{64}$ The constant phase element provided the best fit of the measured and modelled data.

The value of $\mathrm{C}_{\mathrm{CPE}}$ shows a notable increase in going from control PEDOT to the nano-Ni/rGO film, to the PEDOT/nano-Ni/rGO film, without and, then, with light illumination. This indicates that the $\mathrm{PEDOT} /$ nano-Ni/rGO film had a slightly greater active area than the nano-Ni/rGO film, and a much greater active area than the control PEDOT alone. Illumination of the PEDOT/nano-Ni/rGO with light still further increased its active area.

The PEDOT/nano-Ni/rGO also exhibited more efficient catalysis at $-0.75 \mathrm{~V}$ vs $\mathrm{Ag} / \mathrm{AgCl}$, as demonstrated by a lower $\mathrm{R}_{\mathrm{ct}}\left(173.8 \Omega \mathrm{cm}^{2}\right.$ with light illumination; vs $189.5 \Omega \mathrm{cm}^{2}$ without light illumination and $265.6 \Omega \mathrm{cm}^{2}$ for the nano-Ni/rGO film). The control PEDOT was substantially less active as evidenced by very high $R_{c t}$ values (1005 $\Omega$ $\mathrm{cm}^{2}$ with light illumination, and $749.2 \Omega \mathrm{cm}^{2}$ without light illumination). The ohmic resistance $R_{\circ}$ was similar for each sample, falling in the range $42.43-45.84 \Omega \mathrm{cm}^{2}$.

Figure 9 depicts Tafel plots for the catalysts, with results tabulated in the last two columns of Table 1.

The exchange current density, $i_{0}$, indicates the (intrinsic) catalytic rate of each material at the reversible potential, with an overpotential of zero. As can be seen, the control PEDOT exhibited the highest $i_{o}$ indicating it to be a good HER catalyst $\left(14.80 \mu \mathrm{A} / \mathrm{cm}^{2}\right.$ without light illumination; $15.74 \mu \mathrm{A} / \mathrm{cm}^{2}$ with light illumination). The nano-Ni/rGO (without PEDOT) exhibited the highest $i_{0}$ of the metal-containing catalysts $\left(9.07 \mu \mathrm{A} / \mathrm{cm}^{2}\right)$, with the bare Pt control following behind $\left(7.02 \mu \mathrm{A} / \mathrm{cm}^{2}\right)$. The PEDOT/nano-Ni/rGO samples with and without light illumination were, in fact, the least intrinsically active. However, their lower Tafel slopes (A), particularly that of PEDOT/nano-Ni/rGO under light illumination, meant that their catalytic activity was more strongly accelerated by the applied bias than the control nano-Ni/rGO and control $\mathrm{Pt}$ samples.

The catalytic activity at $-0.75 \mathrm{~V}(\mathrm{vs} \mathrm{Ag} / \mathrm{AgCl})$ was $3.6 \mathrm{~mA} / \mathrm{cm}^{2}$ for PEDOT/nano-Ni/rGO vs. $2.1 \mathrm{~mA} / \mathrm{cm}^{2}$ for the same quantities of nano- $\mathrm{Ni} / \mathrm{rGO}$ without the PEDOT. That is, the presence of the PEDOT increased the catalytic rate by $1.5 \mathrm{~mA} / \mathrm{cm}^{2}$, which equates to 
a $71 \%$ increase. The PEDOT/nano-Ni/rGO was also $64 \%$ more active than a benchmark, control bare $\mathrm{Pt}$ electrode under identical conditions, which produced $2.2 \mathrm{~mA} / \mathrm{cm}^{2}$. The above thin-film appears to be the most active PEDOT-based HER catalyst yet reported as a proportion of the catalytic activity of Pt under the same conditions.

Accordingly, it can be concluded that the catalytic amplification exhibited by the PEDOT/nano-Ni/rGO film relative to the PEDOTfree nano-Ni/rGO control derived from a larger active area that was, additionally, strongly activated by the voltage bias (yielding a lower Tafel slope).

\section{The Mechanism and Origin of the Catalytic Amplification}

At $-0.75 \mathrm{~V}$, PEDOT is in its non-conducting form, meaning that it does not formally have a capacity to conduct electrons. However, in this state, PEDOT is an excellent hole $\left(\mathrm{h}^{+}\right)$ transport material, meaning that holes formed on the PEDOT backbone can migrate to the FTO surface.

The catalytic mechanism therefore likely involved protons $\left(\mathrm{H}^{+}\right)$being converted to hydrogen $\left(\mathrm{H}_{2}\right)$ on catalytic sites in the thin film coating, with electrons being extracted from a nearby PEDOT monomer to facilitate this process. The resulting holes $\left(\mathrm{h}^{+}\right)$then migrated along the PEDOT chain to the surface of the FTO slide, where they were quenched by electrons provided via the external circuit. The rate at which holes formed and migrated through the PEDOT to the external circuit would, undoubtedly, have been strongly affected by the applied bias. Instead of the PEDOT acting as an electron conductor, it therefore appears to have acted as a semi-conductor, providing electrons and transporting the resulting holes to the external circuit.

While the mechanism of charge transport by the PEDOT did not involve electron conduction, it is, nevertheless, clear that the catalytic amplification exhibited by the PEDOT/nano$\mathrm{Ni} / \mathrm{rGO}$ film relative to the nano-Ni/rGO control (without PEDOT), derived from a larger active area that was, additionally, more strongly activated by the voltage bias (yielding a lower Tafel slope). That is, in connecting the maximum number of catalytically active sites to the external circuit, the PEDOT maximally increased the electrochemically active area of the catalyst. In providing a pathway for charge carrier exchange from each of those catalytic sites to the external circuit, the PEDOT also made each catalytic site more responsive to the applied bias (i.e. it better transmitted the bias). It did this by acting like a semiconductor.

The question that then arises is: why was there the extreme sensitivity to the precise quantity of $\mathrm{rGO}$ present? That is, why did the inclusion of $5.4 \mathrm{mg} \mathrm{rGO}$ yield a notably higher current density than $6.0 \mathrm{mg}$ or $4.8 \mathrm{mg}$ ? Comparisons of the EIS data of the above films were inconclusive in respect of explaining their different catalytic performances.

A possible clue in this respect may be found in a comparison of the thicknesses and (electron) conductivities of the different films. As shown in Table 2, the coating with $5.4 \mathrm{mg}$ rGO was notably thinner than the coating with $6.0 \mathrm{mg}$ rGO. However, the (electron) conductivity and therefore, likely, also the hole transport

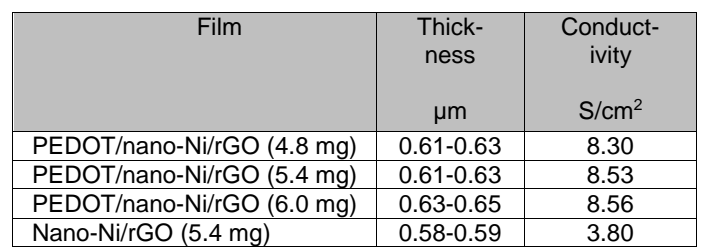

Table 2.Measured conductivity and thickness of the PEDOT thin films containing $125 \mathrm{mg}$ nano- $\mathrm{Ni}$ and $4.8 \mathrm{mg}, 5.4 \mathrm{mg}$, or $6.0 \mathrm{mg}$ rGO.

properties, of the two coatings were very similar (both being broadly controlled by the linearity of the PEDOT chains). By contrast, the coating with $4.8 \mathrm{mg}$ rGO was also thin, but its conductivity, and therefore, likely, also its hole transport capability was notably lower. This data therefore suggests that the coating with $5.4 \mathrm{mg} \mathrm{rGO}$ combined the thinnest layer with the highest hole transport conductivity. That is, it appears that this coating combined the highest density of catalytic sites with the shortest pathway for charge carrier movement to the external circuit. While the coatings swell and become thicker during operation, as noted earlier, this seems to involve the PEDOT itself opening up to form vacant, nanoscopic pores, so that the structure of the body of the coating does not seem to change significantly.

The synergistic effect therefore appears to have derived from a very particular ratio of catalyst density to film conductivity and thickness. In this respect, the above results conform with the concept ${ }^{11}$ that a thin-film conducting polymer may potentially be induced to amplify catalytic performance by optimizing the ratio of catalyst density to film conductivity and thickness.

\section{Conclusions}

Thin, vapour phase polymerized PEDOT films containing nano$\mathrm{Ni}$ and rGO, on FTO glass, were examined as (photo)electrocatalysts of hydrogen generation. Composite thin-films incorporating PEDOT : nano-Ni : rGO having 5.6 (C; PEDOT) : 1 (Ni) : 5.2 (C; rGO) molar ratios yielded current densities of $3.6 \mathrm{~mA} / \mathrm{cm}^{2}$ (including ca. $200 \mu \mathrm{A} / \mathrm{cm}^{2}$ due to light illumination) after $3 \mathrm{~h}$ at $-0.75 \mathrm{~V}(\mathrm{vs} \mathrm{Ag} / \mathrm{AgCl})$ under 0.25 sun in $0.05 \mathrm{M} \mathrm{H}_{2} \mathrm{SO}_{4} / 0.2 \mathrm{M} \mathrm{Na}_{2} \mathrm{SO}_{4}$. The PEDOT substrate of the above film made a substantial contribution to this catalytic performance as demonstrated by the fact that, under identical conditions after $3 \mathrm{~h}$, a nano-Ni/rGO film of equivalent composition, that did not contain PEDOT, generated only 2.1 $\mathrm{mA} / \mathrm{cm}^{2}$. Moreover, a comparable Pt thin film yielded only 2.2 $\mathrm{mA} / \mathrm{cm}^{2}$ after $3 \mathrm{~h}$ under identical conditions. Equivalent control PEDOT, PEDOT/nano-Ni, and PEDOT/rGO films were an order of magnitude less catalytically active. Studies indicated that the PEDOT brought about the amplification by connecting the largest number of catalytic sites (nano-Ni) by the shortest possible pathways to the external circuit. The rGO may also have acted as catalytic sites. Gas chromatography confirmed that hydrogen was the sole gas produced by the most active PEDOT/nano-Ni/rGO thin film. SEM/EDX indicated that the above film displayed a structure, in which the PEDOT largely bridged and bound the component materials present. TEM indicated that the PEDOT formed an apparently seamless 
interface with the nano-Ni lattice and rGO platelets. XRD and XPS analyses confirmed the elemental composition and chemical structure of the composite. In demonstrating that a particular ratio of catalyst density to film conductivity and thickness was needed for the observed catalytic amplification, this work was consistent with earlier propositions to the same effect. ${ }^{11}$ The extreme sensitivity of the catalytic amplification to the precise composition of the thin film attests to the synergistic nature of the effect.

\section{Experimental}

\section{Materials and Techniques}

The following materials were used (Supplier): Fluorine-doped tin oxide (FTO) slides (Zhuhai Kaivo Electronic Components Co.); glass microscope slides (Australia Optics); iron(III) p-toluenesulfonate (Fe(III)-pTS) (technical grade, Sigma Aldrich Co.); 3,4ethylenedioxythiophene (EDOT) (97\%, Sigma Aldrich Co.); graphite flakes (3772) (Asbury Graphite Mills USA), Ni nanoparticles (99.9\%, 20 nm; Skyspring Nanomaterials, Houston).

FTO and glass substrates were cleaned using a PLAMAFLO PDCFMG Plasma cleaner and a DIG UV PSD PR SERIES digital UV Ozone cleaner. Sonication was carried out using a B2500R-MTH sonicator. Spin-coating onto the substrates was carried out using a WS-400B6NPP/LITE spin-coater. Centrifugation-washing steps were carried out using using a ProSciTech TG16WS centrifuge.

Thickness measurements were made using a Vccco Dektak 150 profilometer. The electrical resistivity of the films after deposition, were measured on a non-conducting glass slide using an HG29315 Jandel equipped with a four-point probe. The resistivity (in $\Omega / \square$ ) was calculated using the formula $\rho=t \cdot R_{\mathrm{s}}$, where $\rho$ is resistivity, $t$ is sheet thickness and $R_{\mathrm{s}}$ is sheet resistance. Resistivity can then be converted to conductivity $(\mathrm{S} / \mathrm{cm})$. Scanning Electron Microscopy (SEM) and Transmission Electron Microscopy (TEM) images were taken using a JEOL 7500 FESEM. Elemental analysis was done by the Campbell Microanalytical laboratory at the University of Otago, New Zealand. Powder X-ray diffraction (XRD) patterns of GO, rGO, PEDOT and PEDOT/nano-Ni/rGO were recorded on a GBC MMA instrument using $\mathrm{Cu} \mathrm{K} \alpha$ radiation with $\lambda=1.5418 \AA$ at scan rate of $2 \%$ min over the range $8-80^{\circ}$. X-ray photoelectron spectroscopy was carried out on a PHI660 instrument using a monochromatic Mg Ka $\mathrm{X}$-ray source.

\section{GO synthesis}

In order to prepare fully oxidized graphite, dry expandable graphite flakes were first thermally treated at $700{ }^{\circ} \mathrm{C}$ in a vertical tube furnace under $\mathrm{N}_{2}$ atmosphere. The resulting expanded graphite (EG) was used as a precursor for $\mathrm{GO}$ synthesis, following previously described methods. ${ }^{65-69}$ Briefly, $1 \mathrm{~g}$ of EG and $200 \mathrm{~mL}$ of $\mathrm{H}_{2} \mathrm{SO}_{4}$ were mixed and stirred in a flask for $24 \mathrm{~h} . \mathrm{KMnO}_{4}(5 \mathrm{~g})$ was then added to the mixture slowly. The mixture was transferred into an ice bath and $200 \mathrm{~mL}$ of DI water containing $50 \mathrm{~mL}$ of $30 \% \mathrm{H}_{2} \mathrm{O}_{2}$ were poured slowly into the mixture. The suspension changed colour to light brown. After stirring for another $30 \mathrm{~min}$, the resulting $\mathrm{GO}$ particles were washed and centrifuged with a $\mathrm{HCl}$ solution (9:1 water: $\mathrm{c} . \mathrm{HCl}$ by volume), then centrifuged again and washed with DI water until the $\mathrm{pH}$ of the solution became 3 - 4 . The resultant $\mathrm{GO}$ sheets were dispersed in deionized water by gentle shaking. Then, a GO dispersion in ethanol was prepared by extracting the water from the parent aqueous GO dispersion by repeated centrifugationwashing steps (6 times, for $10-30 \mathrm{~min}$ each, at $11000 \mathrm{rpm}) .{ }^{70}$ The parent aqueous $\mathrm{GO}(15 \mathrm{~mL})\left(\sim 2.5 \mathrm{mg} \mathrm{ml}^{-1}\right)$ was poured into a $50 \mathrm{ml}$ centrifuge tube (Nalgene), to which $20 \mathrm{ml}$ ethanol was added, followed by vigorous mixing using a vortex shaker. After each centrifuging, $30 \mathrm{ml}$ of the supernatant was poured off and replaced with $30 \mathrm{ml}$ of ethanol and then mixed vigorously by vortex shaking. This process was repeated a further 5 times to replace the water with ethanol. Finally, the dispersion was sonicated in a bath sonicator for $1 \mathrm{~h}$ before being centrifuged again to make a high concentration dispersion ( $\sim 30 \mathrm{mg} / \mathrm{ml} \mathrm{GO}$ ).

\section{Preparation of PEDOT, PEDOT/nano-Ni, PEDOT/rGo, PEDOT/nano-}

\section{$\mathrm{Ni} / \mathrm{rGO}$ and Nano-Ni/rGO on FTO-coated glass slides}

Uncoated glass and FTO-coated glass slides were immersed in acetone within a TLC chamber. The baths with the immersed slides were sonicated for $90 \mathrm{~min}$, whereafter the slides were washed with water and dried by blowing air over them. The FTO and uncoated glass slides were then labelled. All slides were thereafter treated in a digital ozone-UV cleaner for $20 \mathrm{~min}$ to remove organic contaminants. The slides were then cleaned in a plasma cleaner in order to functionalize groups on the slide's surface with which to fix the coated chemical solutions during spin-coating. The FTO and glass substrates were heated to dryness on an IKA ${ }^{\circledR} \mathrm{RCT}$ basic hotplate at $60^{\circ} \mathrm{C}$.

To prepare the PEDOT, PEDOT/nano-Ni, PEDOT/rGO, and PEDOT/nano-Ni/rGO films on FTO glass slides, the following procedure was used. Where applicable, GO ethanol solution (e.g. $0.2 \mathrm{ml}$ ) was transferred to a small glass vial and the volume increased to $1.2 \mathrm{ml}$ by adding absolute ethanol. The solution was sonicated for $10 \mathrm{~min}$ and then stirred with a magnetic stirrer for 5 min. Where applicable, Nano-Ni (e.g. $125 \mathrm{mg}$ ) was added gradually with magnetic stirring continuing for $2.5 \mathrm{~h}$ thereafter. A solution of dissolved Fe(III)-PTS $(100 \mathrm{mg}$ ) in $0.15 \mathrm{ml}$ ethanol was then added to the mixture. The resulting solution $(100 \mu \mathrm{L})$ was dropcast onto the slide surface using a micropipette. The slides were then spun at 2000 revolutions per minute $(\mathrm{rpm})$ for $180 \mathrm{~s}$. After spin-coating, the sample was quickly transferred to a hotplate, where it was dried at $60{ }^{\circ} \mathrm{C}$ for $15 \mathrm{~min}$.

Vapour phase polymerisation was carried out in a separate conical flask (500 $\mathrm{mL}$ capacity), equipped with a rubber stopper containing a crocodile clip suspended above the bottom of the flask. EDOT $(0.450 \mathrm{~mL})$ was placed in the flask and the dried, spincoated FTO or uncoated glass substrates were held above the EDOT solution by the crocodile clip, with the stopper in place. The stoppered conical flask was then placed in an oven at $60^{\circ} \mathrm{C}$ for 60 min, during which time the EDOT vapour polymerised into PEDOT polymer on the slide surface. After polymerisation was complete, the sample was removed, washed thoroughly with ethanol, and then left to dry overnight. A representative film of this type was $0.67 \mathrm{~mm}$ thick, with a conductance of $8.3 \mathrm{~S} / \mathrm{cm}$ (on non-conducting glass). 
The resulting dried FTO-coated samples were converted to usable electrodes by attaching a copper wire to the FTO surface with conductive silver paint and epoxy resin. When the silver paste was fully solidified, epoxy glue was used to cover the contact area of the wire as well as any exposed clean FTO glass surface.

Control nano-Ni/GO films on FTO were prepared by a similar process, without adding $\mathrm{Fe}$ (III)-PTS to the spin-coating solution or exposing the spin-coated layer to EDOT vapour. The spin-coated nano-Ni/GO films proved to be robustly attached to the FTO glass and durable to subsequent electrochemical testing.

Immediately prior to testing as a (photo)electrocatalyst, the GO present in all films was reduced electrochemically to $\mathrm{rGO}$ using cyclic voltammetry (performed in $0.2 \mathrm{M} \mathrm{Na}_{2} \mathrm{SO}_{4}(\mathrm{pH}$ 12); 5 cycles between -1.2 to $0.8 \mathrm{~V}$, vs. $\mathrm{Ag} / \mathrm{AgCl}$, at $50 \mathrm{mV} / \mathrm{s}$ scan speed) (Figure S5, Figure S6).

Studies of PEDOT/Nano-Ni, PEDOT/Nano-Ni/rGO and Nano-

\section{$\mathrm{Ni} / \mathrm{rGO}$ on FTO as HER Photocatalysis}

The resulting nanocomposite mixtures on the FTO-coated glass slides were employed as working electrodes within a fully-enclosed quartz cell $(5 \times 5 \times 5 \mathrm{~cm})$ placed inside a closed cabinet that comprised a Faraday cage. A Pt mesh $(1 \times 2 \mathrm{~cm})$ was used as the counter electrode. A BASi $\mathrm{Ag} / \mathrm{AgCl}$ aqueous salt bridge $(\mathrm{KCl}, 3 \mathrm{M})$ served as reference electrode. The electrolyte employed was a 0.2 $\mathrm{M} \mathrm{Na}_{2} \mathrm{SO}_{4} / 0.05 \mathrm{M} \mathrm{H}_{2} \mathrm{SO}_{4}$ aqueous solution, adjusted to $\mathrm{pH} 1$ by adding $\mathrm{H}_{2} \mathrm{SO}_{4}$. The electrolyte was bubbled with $\mathrm{N}_{2}$ gas for $30 \mathrm{~min}$ before each experiment. Linear sweep voltammetry (LSV), cyclic voltammetry (CV) and chronoamperograms (CA) were performed using an EDAQ466 potentiostat. Where applicable, the sample was illuminated with a SoLux daylight MR16 halogen light bulb (12 V, 50 W, 24; 0.25 sun intensity) with a stable output range of $275-750$ $\mathrm{nm}$. The light was placed $10 \mathrm{~cm}$ from the working electrode. A Thorlabs visible-light bandpass filter $(315-710 \mathrm{~nm})$ was placed 1.5 $\mathrm{cm}$ in front of the light source. The bandpass filter removed any heat (infra-red wavelengths) generated by the light source.

Electrochemical Impedance studies (EIS) were conducted potentiostatically at $-0.75 \mathrm{~V}$ (vs. $\mathrm{Ag} / \mathrm{AgCl})$ under the same conditions as the amperometric studies, with the same light source, applying frequencies between $0.1 \mathrm{~Hz}$ and $150 \mathrm{KHz}$.

\section{Gas Analysis Studies}

Photocurrent testing of high performing PEDOT/Nano-Ni/rGO samples on FTO glass with simultaneous gas analysis was performed using a custom-built apparatus. The apparatus, which is depicted in Figure S1, comprised of a fully-enclosed electrochemical cell containing two sealed, gas-tight half-cells whose electrolytes were separated only by a Nafion 117 proton exchange membrane $(5 \times 4$ $\mathrm{cm})$. The one half cell contained the working electrode sample and a $\mathrm{Ag} / \mathrm{AgCl}$ reference electrode. The other half-cell contained the Pt mesh counter electrode. One wall of the former half-cell was a quartz sheet. Illumination from the above light source was passed through the quartz sheet onto the working electrode. The incident light was filtered with the above bandpass filter. The electrodes were connected to a $\mathrm{CHI}$ potentiostat. The gas outlets for the working and counter electrode were connected with stainless steel tubing to sample loops connected to a dedicated Shimadzu GC-8A gas chromatograph.

After fitting the electrodes, both half cells were filled with electrolyte. The electrolyte in each half cell was then separately purged with Ar gas overnight to remove all air inside the cell (without a voltage or light-illumination being applied to the cell). Thereafter, the Ar passing through each half cell was sampled, injected and analysed using the attached gas chromatograph, with the results plotted over $30 \mathrm{~min}$ of elution time. The analyses verified that there was no gas other than $\mathrm{Ar}$ in the gas streams passing through each half-cell. The Ar gas, which was continuously bubbled through the electrolyte throughout the photocurrent experiment, acted as a carrier gas for the connected GC.

Voltage and light-illumination was then applied to the cell, whereafter the carrier gas was tested as described above, for electrocatalysis product gases using the GC. The identities of the gases in the carrier Ar were determined by their retention times. GC testing of this type, after illumination and biasing, provided a quantitative measure of the gases produced by photoelectrochemical activity of the samples.

\section{Conflicts of interest}

There are no conflicts to declare.

\section{Acknowledgements}

MA thanks the Government of Iraq for a PhD scholarship. The authors thank A/Prof Attila Mozer of the University of Wollongong for use of a GC gas analyser. The authors acknowledge the Australian National Fabrication Facility (ANFF) Materials Node for equipment use and Mr Adam Taylor for design and printing of the custom-built apparatus. Support from the Australian Research Council Centre of Excellence Scheme (Project Number CE140100012) is gratefully acknowledged. The authors acknowledge use of facilities and the assistance of Tony Romeo within the University of Wollongong Electron Microscopy Centre. This research used equipment funded by the Australian Research Council (ARC) Linkage, Infrastructure, Equipment and Facilities (LIEF) grant LE160100063 located at the University of Wollongong Electron Microscopy Centre.

\section{Notes and references}

1 A. Züttel, A. Remhof, A. Borgschulte, O. Friedrichs, Phil. Trans. R. Soc. A., 2010, 368, 3329.

2 J. M. Ogden, Phys. Today 2002, 55, 69.

3 C. S. W. Jeffrey, H. Chao-Wei, L. Chi-Hung Catal. 2012, 2, 490.

4 G. Grace, Petroleum Rev. 2004, 57, 32.

5 (a) M. Alsultan, A. Ranjbar, G. F. Swiegers, G. G. Wallace, S. Balakrishnan, J. Huang, Chap 11 in Industrial Applications for Intelligent Polymers and Coatings, M. Hosseini, A. S. H. Makhlouf (eds.), Springer International Publishing, Switzerland, 2016, and refs therein; (b) B. Winther-Jensen, D. R. MacFarlane, Energy Environ. Sci., 2011, 4, 2790.

6 X. Long, Z. Wang, T. Zhang, S. Xiao, S. Yang, G. Li, H. Zhu, W. Guo, J. Am. Chem. Soc. 2015, 137, 11900; O. Pyshkina, A. 
Kubarkov, V. Sergeyev, Mat. Sci. Appl. Chem. 2010, 21, 51; A Kros, N. A. J. M. Sommerdijk, R. M. Nolte, Sens. Actuators 2005, 106, 289; C. Carlberg, X. Chen, O. Inganäs, Solid State lonics, 1996, 85, 73.

7 (a) C. Gu, B. Norris, F. Fan, C. Bielawski, A. Bard, ACS Catalysis, 2012, 2, 746; (b) B. Winther-Jensen, K. Fraser, C. Ong, M. Forsyth, D. R. MacFarlane, Adv. Mater., 2010, 22, 1727.

8 K. Xie, H. Wu, Y. Meng, K. Lu, Z. Wei, Z. Zhang, J. Mater Chem., 2015, 3, 78.

9 R. K. Pandey, V. Lakshminarayanan, J. Phys. Chem. C, 2010, 114, 8507.

10 X. Li, W. Lu, W. Dong, Q. Chen, D. Wu, W. Zhou, L. Chen, Nanoscale, 2013, 5, 5257.

11 M. Alsultan, S. Balakrishnan, J. Choi, R. Jalili, P. Tiwari, P. Wagner, G. F. Swiegers submitted for publication

12 G. Wang, B. Wang, J. Park, J. Yang, X. Shen, J. Yao, Carbon 2009, 47, 68. K. Haubner, J. Murawski, P. Olk, L. Eng, C. Ziegler, B. Adolphi, E. Jaehne, ChemPhysChem. 2010, 11, 2131.

13 I. Khalil, N. M. Julkapli, W. A. Yehye, W. J. Basirun, S. K. Bhargava, Materials 2016, 9, 406.

14 D. Sharma, S. Kanchi, M. I. Sabela, K. Bisetty, Arab. J. Chem., 2016, 9, 238

15 B. Devadas, M. Rajkumar, S.-M. Chen, R. Saraswathi, Int. J. Electrochem. Sci., 2012, 7, 3339.

16 K. H. Kim, M. Yang, K. M. Cho, Y. S. Jun, S. B. Lee, H. T. Jung, Sci. Rep. 2013, 3, 3251.

17 A number of HER catalysts incorporating $\mathrm{rGO}$ have been reported; see for example: (a) G. Xie, K. Zhang, B. Guo, Q. Liu, L. Fang, J. R. Gong, Adv. Mater. 2013, 25, 3820, and ref. therein; (b) X. Zou, Y. Zhang, Chem. Soc. Rev. 2015, 44, 5148 and ref. therein. Space precludes a full listing of HER catalysts incorporating $\mathrm{rGO}$; representative examples are provided in ref. 18-24.

18 Y. Li, H. Wang, L. Xie, Y. Liang, G. Hong, H. Dai, J. Am. Chem. Soc. 2011, 133, 7296

19 F. Meng, J. Li, S. K. Cushing, M. Zhi, N. Wu, J. Am. Chem. Soc. 2013, 135, 10286; H. Tang, K. Dou, C.-C. Kaun, Q. Kuanga, S. Yang, J. Mater. Chem. A, 2014, 2, 360; X. Zheng, J. Xu, K. Yan, H. Wang, Z. Wang, S. Yang, Chem. Mater. 2014, 26, 2344; C.B. Ma, X. Qi, B. Chen, S. Bao, Z. Yin, X.-J. Wu, Z. Luo, J. Wei, H.-L. Zhang, H. Zhang, Nanoscale, 2014, 6, 5624; S. Peng, L. Li, X. Han, W. Sun, M. Srinivasan, S. G. Mhaisalkar, F. Cheng, Q. Yan, J. Chen, S. Ramakrishna, Angew. Chem. Int. Ed. 2014 53, 12594; Y.-J. Tang, M.-R. Gao, C.-H. Liu, S.-L. Li, H.-L. Jiang, Y.-Q. Lan, M. Han, S.-H. Yu, Angew. Chem. Int. Ed. 2015, 54, 12928; Y. Li, H. Wang, S. Peng, J. Phys. Chem. C 2014, 118, 19842.

20 H. Yan, C. Tian, L. Wang, A. Wu, M. Meng, L. Zhao, H. Fu, Angew. Chem. Int. Ed. 2015, 54, 6325

21 L. Jiao, Y.-X. Zhou, H.-L. Jiang, Chem. Sci., 2016, 7, 1690; L. Ma, X. Shen, H. Zhou, G. Zhu, Z. Jia, K. Chen, J. Mater. Chem. A, 2015, 3, 5337; Y. Pan, N. Yang, Y. Chen, Y. Lin, Y. Li, Y. Liu, C. Liu, J. Power Sources, 2015, 297, 45

22 S. Chandrasekaran, W. Choi, J. Chung, S. Hur, E. Kim, Mater Lett. 2014, 136, 118; Y. Li, H. Wang, S. Peng, J. Phys. Chem C. 2014, 118, 19842

23 X. Liu, W. Liu, M. Ko, M. Park, M. G. Kim, P. Oh, S. Chae, S. Park, A. Casimir, G. Wu, J. Cho, Adv. Funct. Mater. 2015, 25, 5799; J. Zhang, Q. Wang, L. Wang, X. Li, W. Huang, Nanoscale, 2015, 7, 10391; D. Chanda, J. Hnat, A. Dobrota, I. Pasti, M. Paidar, K. Bouzek, Phys. Chem. Chem. Phys., 2015, 17, 26864.

24 R. Chen, Y. Song, Z. Wang, Y. Gao, Y. Sheng, Z. Shu, J. Zhang, X. Li, Cat. Commun., 2016, 85, 26; B. Rezaei, A. Jahromi, A. Ensafi, Electrochimica Acta., 2016, 213, 423. Y. Tang, Y. Wang, X. Wang, S. Li, W. Huang, L. Dong, C. Liu, Y. Li, Y. Lan,
Adv. Energy Mater., 2016, 6, 1; D. Chen, L. Zou, S. Li, F. Zheng, Sci. Rep., 2016, 6, 20335;

25 J. Chen, P. W. Wagner, L. Tong, D. Boskovic, W. Zhang, D. L. Officer, G. G. Wallace, G. F. Swiegers, Chem. Sci., 2013, 4, 2797.

26 See, for example: J. Chen, J. Huang, G. F. Swiegers, C. O. Too, G. G. Wallace, Chem. Commun. 2004, 308.

27 Z.-A. Hu, Y.-L. Xie, Y.-X. Wang, H.-Y. Wu, Y.-Y. Yang, Z.-Y. Zhang, Electrochim. Acta, 2009, 54, 2737.

28 X. Liu, J. Huang, X. Wei, C. Yuan, T. Liu, D. Cao, J. Yin, G. Wang, J. Power Sources, 2013, 240, 338.

29 Y. Zhao, S. He, M. Wei, D. G. Evans, X. Duan, Chem. Commun., 2010, 46, 3031.

30 J. Xu, S. Gai, F. He, N. Niu, P. Gao, Y. Chen, P. Yang, J. Mater. Chem. A, 2014, 2, 1022.

31 K. Satheesh, R. Jayavel, Mater. Lett. 2013, 113, 5.

32 R.Gupta, Z. Alahmed, F. Yakuphanoglu, Mater. Lett., 2013, 112, 75.

33 T. Kavinkumar, S. Manivannan, Ceramics International, 2016, 42, 1769.

34 K. Muthoosamy, R. Geetha Bai, S. Sudheer, S. Manickam, I. Abubakar, H. Loh, H. Lim, N. Huang, C. Chia, Int. J. Nanomedicine, 2015, 10, 1505.

35 M. Zong, Y. Huang, Y. Zhao, X. Sun, C. Qu, D. Luo, J. Zheng, RSC Adv., 2013, 45, 23638.

36 Y. C. Si , E. T. Samulski, Chem. Mater., 2008, 20, 6792.

37 L. Zhang, R. Jamal, Q. Zhao, M. Wang, T. Abdiryim, Nanoscale Res. Lett. 2015, 10, 148.

38 S. Jo, Y. Lee, J. Yang, W. Jung, J. Kim. Synth. Met., 2012, 162, 1279.

39 Z. Jiang, J. Xie, D. Jiang, X. Wei, M. Chen, CrystEngComm, 2013, 15, 560.

40 Z. Wei, J. Ma, W. Feng, J. Dai, Q. Wang, T. Xia, P. Yan, Mater. Characterization, 2007, 58, 1019.

41 K. Dave, K. H. Park, M. Dhayal, RSC Adv., 2015, 5, 95657.

42 J. Lu, Y. Li, S. Li, S. Jiang, Scientific Reports, 2016, 6, Article Number: 21530.

43 D. Mhamane, M. Kim, H. Kim, D. Ruan, K. Kim, V. Aravindan, M. Srinivasan, K. Roh, S. Lee, J. Mater. Chem. A, 2016, 4, 15, 5578.

44 K. Yuan, M. Forster, U. Scherf, Y. Xu, M. Que, Y. Chen, J. Uihlein, T. Chassé, G. Brunklaus, L. Shi, T. Pichler, R. Heiderhoff, T. Riedl, Adv. Mater., 2015, 27, 6714.

45 A. Shaikh, S. Parida, S. Böhm, RSC Adv., 2016, 6, 100383

46 P. Benjwal, P. Chamoli, K. Kar, M. Kumar, RSC Adv., 2015, 5, 73249 .

47 L. Wang, Y. Li, Z. Han, B. Qian, X. Jiang, G. Yang, L. Chen, J. Pinto, J. Mater. Chem. A, 2013, 1, 8385.

48 J. E. Choe, M. S. Ahmed, S. Jeon, J. Power Sources, 2015, 281, 211.

49 H. Park, S. J, Lee, S. Kim, H. W. Ryu, S. H. Lee, H. H. Choi, I. W, Cheong, J. Kim, Polymer, 2013, 54, 4155.

50 M. Wang, M. Zhou, L. Zhu, Q., Li, C. Jiang, Solar Energy, 2016 129, 175.

51 T. Ji, L. Tan, X. Hu, Y. Dai, Y. Chen, Phys. Chem. Chem. Phys., 2015, 17, 4137.

52 A. Kanwat, J. Jang, J. Mater. Chem. C, 2014, 2, 901.

53 A. Bagri, V. Shenoy, C. Mattevi, M. Chhowalla, M. Acik, Y. Chabal, Nature Chem., 2010, 2, 581.

54 V. Sridhar, I. Lee, H. Chun, H. Park, RSC Adv., 2015, 5, 68270.

55 Z. Xing, Z. Ju, Y. Zhao, J. Wan, Y. Zhu, Y. Qiang, Y. Qian, Scientific Reports, 2016, 6, Article Number: 26146.

$56 \mathrm{H}$. Yu, B. Zhang, C. Bulin, R. Li, R. Xing, 2016, Scientific Reports, 2016, 6, Article Number: 36143.

57 A. A. Ensafi, E. Heydari-Soureshjani, M. Jafari-Asl, B. Rezaei, Carbon 2016, 99, 398.

58 H. Nady, M. Negema RSC Adv., 2016, 6, 51111. 
59 Y. Qiang, L. Guo, S. Zhang, W. Li, S. Yu, J. Tan, Scientific Reports, 2016, 6, article number: 33305.

60 F. Fiegenbaum, M. O. de Souza, M. R. Becker, E. M. A. Martini, R. F. de Souza, J. Power Sources, 2015. 280, 12.

61 H. Jafari, K. Akbarzade, I. Danaee, Arabian J. Chem. 2014; DOI: 10.1016/j.arabjc.2014.11.018

62 B. Ren, D. Li, Q. Jin, H. Cui, C. Wang, J. Mater. Chem. A, 2017, 5, 13196.

63 B. Konkena, K. junge Puring, I. Sinev, S. Piontek, O. Khavryuchenko, J. P. Dürholt, R. Schmid, H. Tüysüz, M. Muhler, W. Schuhmann, U.-P. Apfel, Nature Comm. 2016, 7 12269.

64 G. J. Brug, A. L. G. van den Eeden, M. Sluyters-Rehbach, J. H. Sluyters, J. Electroanal. Chem. 1984, 176, 275.

65 D. Esrafilzadeh, R. Jalili, E. Stewart, J. Razal, S. Moulton, G. G. Wallace, S. Aboutalebi, Adv. Funct. Mat., 2016, 26, 3105.

66 R. Jalili, D. Esrafilzadeh, R. Shepherd, J. Chen, J. Razal, G. G. Wallace, S. Aboutalebi, S. Aminorroaya-Yamini, K. Konstantinov, A. Minett, Adv. Funct. Mat., 2013, 23, 5345.

67 R. Jalili, S. H. Aboutalebi, D. Esrafilzadeh, K. Konstantinov, J. M. Razal, S. E. Moulton, G. G. Wallace, Mater. Horiz. 2014, 1, 87.

68 S. Naficy, R. Jalili, S. Aboutalebi, R. Gorkin, K. Konstantinov, P. Innis, G. Spinks, P. Poulin, G. G. Wallace, Mater. Horizon, 2014, 1, 326.

69 S. Gambhir, R. Jalili, D. L. Officer, G. G. Wallace, NPG Asia Mater., 2015, 7, e-186-1.

70 R. Jalili, D. Esrafilzadeh, S. Moulton, J. Razal, G. G. Wallace, S. Aboutalebi, K. Konstantinov, ACS Nano, 2013, 7, 3981. 